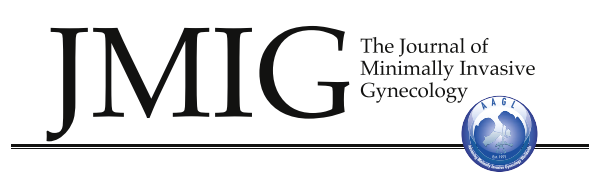

Original Article

\title{
Assessment of Long-Term Bowel Symptoms After Segmental Resection of Deeply Infiltrating Endometriosis: A Matched Cohort Study
}

\author{
Enrique Soto, MD, MSc, Michelle Catenacci, MD, Carrie Bedient, MD, \\ J. Eric Jelovsek, MD, MMEd, and Tommaso Falcone, MD* \\ From the Obstetrics, Gynecology, and Women's Health Institute, Cleveland Clinic, Cleveland, OH (all authors), South Florida Institute for Reproductive \\ Medicine, Miami, FL (Dr. Soto), Department of Obstetrics and Gynecology, Herbert Wertheim College of Medicine at Florida International University, \\ Miami, FL (Dr. Soto), Advanced Fertility Center of Chicago, Chicago, IL (Dr. Catenacci), Fertility Center of Las Vegas, Las Vegas, NV (Dr. Bedient), and \\ Department of Obstetrics and Gynecology, University of Nevada School of Medicine, Las Vegas, NV (Dr. Bedient).
}

ABSTRACT Study Objective: To assess long-term bowel symptoms in women who underwent segmental bowel resection for deepinfiltrating endometriosis (DIE) compared with women who underwent resection of severe endometriosis without bowel resection.

Design: Cohort study with matched controls (Canadian Task Force classification II-2).

Setting: Cleveland Clinic.

Patients: 71 patients (36 cases and 35 controls).

Interventions: Patients who were at least 4 years out from undergoing segmental bowel resection due to DIE were matched with patients who had undergone resection of stage III/IV endometriosis without bowel resection. The patients completed validated questionnaires, and data were analyzed using the Wilcoxon rank-sum, $\chi^{2}$, and Fisher exact tests.

Measurements and Main Results: The Bristol Stool Form Scale, Patient Assessment of Constipation Symptoms Questionnaire (PAC-SYM), and St Mark's Vaizey Fecal Incontinence Grading System were used to elicit information. The median duration of follow-up was 10.1 years (range, 4-18 years). The mean patient age and body mass index were comparable in the cases and the controls. A larger proportion of cases than controls reported new bowel symptoms (58\% [21 of 36] vs $14 \%$ [5 of 35]; $\mathrm{p}=.001$ ), as well as abdominal pain, incomplete bowel movements, and false alarms on the PAC-SYM questionnaire; however, total PAC-SYM and Vaizey Fecal Incontinence Grading System scores were similar in the 2 groups (median, 8 [interquartile range, $8-10$ ] vs 8 [8-10]; $\mathrm{p}=.86$ ). Similarly, the proportion of patients with normal stool consistency (Bristol Stool Form Scale score 2-6) was similar in the 2 groups (80.6\% [29 of 36] vs $94.3 \%$ [33 of 35]; $p=.59$ ).

Conclusion: Segmental bowel resection for DIE may be associated with a higher incidence of new bowel symptoms (possibly due to abdominal pain, incomplete bowel movements, and/or false alarms), but not with worse constipation or fecal incontinence, compared with surgery without bowel resection. Journal of Minimally Invasive Gynecology (2016) 23, 753-759 (C) 2016 AAGL. All rights reserved.

Keywords: $\quad$ Constipation; Deep infiltrating endometriosis; Fecal incontinence; Segmental bowel resection; Severe endometriosis

The authors declare that they have no conflict of interest.

Preliminary findings of the current study were presented at the 68th Annual Meeting of the American Society for Reproductive Medicine, San Diego, CA, October 20 to 24, 2012.

Corresponding author: Tommaso Falcone, MD, FRCS(C), FACOG, Obstetrics, Gynecology and Women's Health Institute, Cleveland Clinic, 9500 Euclid Ave, A81, Cleveland, OH 44195.

E-mail: falcont@ccf.org

Submitted January 25, 2016. Accepted for publication March 4, 2016.

Available at www.sciencedirect.com and www.jmig.org
Endometriosis is a significant cause of both infertility and pelvic pain. Deep infiltrating endometriosis (DIE) is a specific endometriotic lesion that extends more than $5 \mathrm{~mm}$ underneath the peritoneum [1]. Bowel endometriosis is a subtype of DIE and can be located in several locations along the intestines, including the rectum, rectosigmoid junction, colon, cecum, ileocecal junction, appendix, and small bowel [2]. The reported incidence of bowel endometriosis in women with endometriosis varies among studies, ranging from $5.3 \%$ to $12 \%[3,4]$. 
Bowel endometriosis has been associated with gastrointestinal symptoms, such as diarrhea, constipation, rectal bleeding, proctitis, tenesmus, and colic rectal pain that can be chronic or menstrual-related. Bowel endometriosis also has been associated with noncyclic chronic pelvic pain [5]. Surgical removal of bowel endometriosis, often using a minimally invasive approach, can be offered to treat these symptoms [6].

Although bowel resection carriers significant risk to the patient, it can be offered to patients with DIE of the bowel who are experiencing severe symptoms. Bowel resection for endometriosis can be done open or with laparoscopic assistance, with similar outcomes [7]. Complications from the procedure can be considerable, including anemia requiring blood transfusion, anastomotic leakage, fistula formation, and bowel perforation or obstruction [8-10]. Given the significant morbidity associated with bowel resection, the symptomatic benefits need to outweigh the risks of surgery. Several studies with relatively short-term follow up (median $<2$ years) have shown that either operative technique can improve symptoms related to bowel endometriosis, with a resulting improved quality of life [7,9-11]; however, after bowel resection, patients may develop new bothersome symptoms related to the surgery, such as an increase in stools per day or, conversely, constipation or urinary retention $[11,12]$. Patients need to be informed of both the immediate operative risk and any long-term functional changes that could occur as a result of this procedure. The aim of this study was to evaluate the long-term (minimum 4 years) outcomes of patients who underwent segmental bowel resection due to DIE in comparison to controls. Primary outcomes included long-term bowel symptoms, and secondary outcomes included long-term outcome of endometriosis-related symptoms after bowel resection.

\section{Materials and Methods}

This was a matched cohort study involving women who underwent surgical resection of endometriosis between 1993 and 2007 at the Cleveland Clinic. The study protocol was approved by the Cleveland Clinic's Institutional Review Board (IRB 10-899). Procedure and diagnostic codes were used to perform a search for all patients undergoing surgery with a diagnosis of endometriosis between 1993 to 2007 at our institution. A separate electronic search was done to capture patients with endometriosis who underwent bowel resection with a diagnosis of endometriosis during the same time frame. The electronic or paper medical charts of all identified patients were reviewed. Cases were confirmed by reviewing operative and pathology reports. Additional cases that were missed from the initial electronic search were identified through manual review of the charts. Patients who had undergone bowel resection less than 4 years from the date of data collection were excluded. (At least 4 years of follow-up time were required for the study.) Also excluded were any patients who subsequently developed a primary or metastatic pelvic or abdominal malignancy. Potential controls were identified from the chart review and were used for the matching process.

The control group consisted of patients with stage III/IV endometriosis who underwent surgical removal of disease without a bowel resection. These patients had no known endometriosis-related bowel disease and served to evaluate the overall long-term bowel function of patients with severe endometriosis. As with the cases, controls who had undergone surgery less than 4 years from the start of the study were excluded, as were those who subsequently developed a primary or metastatic pelvic or abdominal malignancy. If a patient had undergone more than 1 surgery for endometriosis, the most recent operation was used for matching purposes.

After demographic data were collected, a detailed questionnaire was sent by mail to the identified cases. Patients who did not respond to the initial contact attempt were sent a second questionnaire by mail and were contacted by telephone when this information was available. When the information obtained was incomplete, patients were subsequently contacted by telephone to obtain the missing information. The questionnaire elicited general information regarding indications for the initial surgery and whether additional medical and surgical treatment had been required since the bowel resection. Cases were then asked to rate the severity of symptoms related to endometriosis, such as dysmenorrhea and chronic pelvic pain, both before their surgery and currently. Finally, the survey contained validated and reliable questionnaires pertaining to current bowel function.

Three separate validated questionnaires were incorporated into the patient survey: the Bristol Stool Form Scale, the St. Mark's Vaizey Fecal Incontinence Grading System, and the Patient Assessment of Constipation Symptoms Questionnaire (PAC-SYM). The Bristol Stool Form Scale is a 7-point descriptive visual scale used to assess a patient's most common stool consistency. The patient selects his or her most common stool consistency based on images and text descriptions of the different stool forms, ranging from a separate hard lump to entirely liquid stool. The Bristol Scale Stool Form is a reliable assessment of stool consistency and has been found to correlate with complete gut transit time [13]. The St. Mark's Vaizey Fecal Incontinence Grading System is a standardized scoring system for assessing the severity of fecal incontinence. The questionnaire enquires about the frequency of incontinence of gas, liquid stool, and solid stool. It also assesses the frequency of urge, the use of pads or plugs, and the use of constipating medications to prevent incontinence. The responses are graded to provide an overall severity of fecal incontinence symptoms that have been found to be reproducible and sensitive to changes produced by treatments [14]. The third validated questionnaire included in the patient survey, the PAC-SYM, is designed to assess the severity of constipation. The patient answers 12 questions pertaining to constipation, including assessing for symptoms of incomplete emptying, small bowel movements, hard bowel 


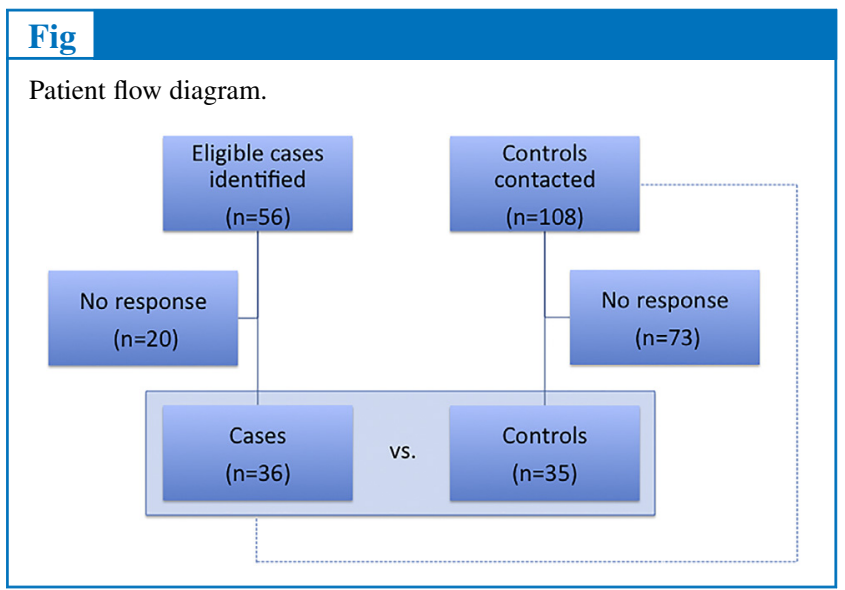

movements, straining, false alarms, and rectal bleeding. The PAC-SYM has found to be a highly reliable and valid tool for assessing constipation symptoms in adults [15]. Permission to use the PAC-SYM questionnaire in our survey was granted by the Janssen Research Foundation.

Once the surveys were returned by the case patients, matching was performed to identify adequate control patients. A logistic regression model was fit to the data using age and year of surgery as the independent variables and $\mathrm{X}$ as the dependent variable. Propensity scores were calculated from the model. Matching was performed using the R package "matching" under several different conditions; the caliper for matching was varied from 0.5 to 1.5 in increments

\begin{tabular}{|c|c|c|c|}
\hline \multicolumn{4}{|l|}{ Table 1} \\
\hline \multicolumn{4}{|c|}{ Patient baseline characteristics } \\
\hline & $\begin{array}{l}\text { Cases } \\
(\mathrm{n}=36)\end{array}$ & $\begin{array}{l}\text { Controls } \\
(\mathrm{n}=35)\end{array}$ & $\begin{array}{l}\mathrm{p} \\
\text { value }\end{array}$ \\
\hline Age, yr, median (IQR) & $37(30.8-39)$ & $34(29.5-41.5)$ & $.74 *$ \\
\hline BMI, median (IQR) & $25(22.3-30)$ & $26.8(21.9-31.5)$ & $.90^{*}$ \\
\hline Race, $\mathrm{n}$ & & & $.02^{\dagger}$ \\
\hline Caucasian & 25 & 31 & \\
\hline African-American & 10 & 2 & \\
\hline Asian & 0 & 0 & \\
\hline Hispanic & 1 & 0 & \\
\hline Other/none listed & 0 & 2 & \\
\hline \multicolumn{4}{|l|}{ Reason for surgery, $\mathrm{n}^{\ddagger}$} \\
\hline Dysmenorrhea & 24 & 26 & $.66^{\S}$ \\
\hline Chronic pelvic pain & 17 & 12 & $.39^{\S}$ \\
\hline Infertility & 12 & 20 & $.07^{\S}$ \\
\hline Bowel pain & 24 & 11 & $.006^{\S}$ \\
\hline Dysuria & 6 & 3 & $.48^{\dagger}$ \\
\hline Other & 2 & 5 & $.26^{\dagger}$ \\
\hline \multicolumn{4}{|c|}{$\begin{array}{l}\text { BMI = body mass index; IQR = interquartile range. } \\
* \text { Wilcoxon rank-sum test with continuity correction. } \\
{ }^{\dagger} \text { Fisher exact test for count data. } \\
\ddagger \text { Multiple answers allowed in the questionnaire. } \\
\S \text { Pearson } \chi^{2} \text { test with Yates continuity correction. }\end{array}$} \\
\hline
\end{tabular}

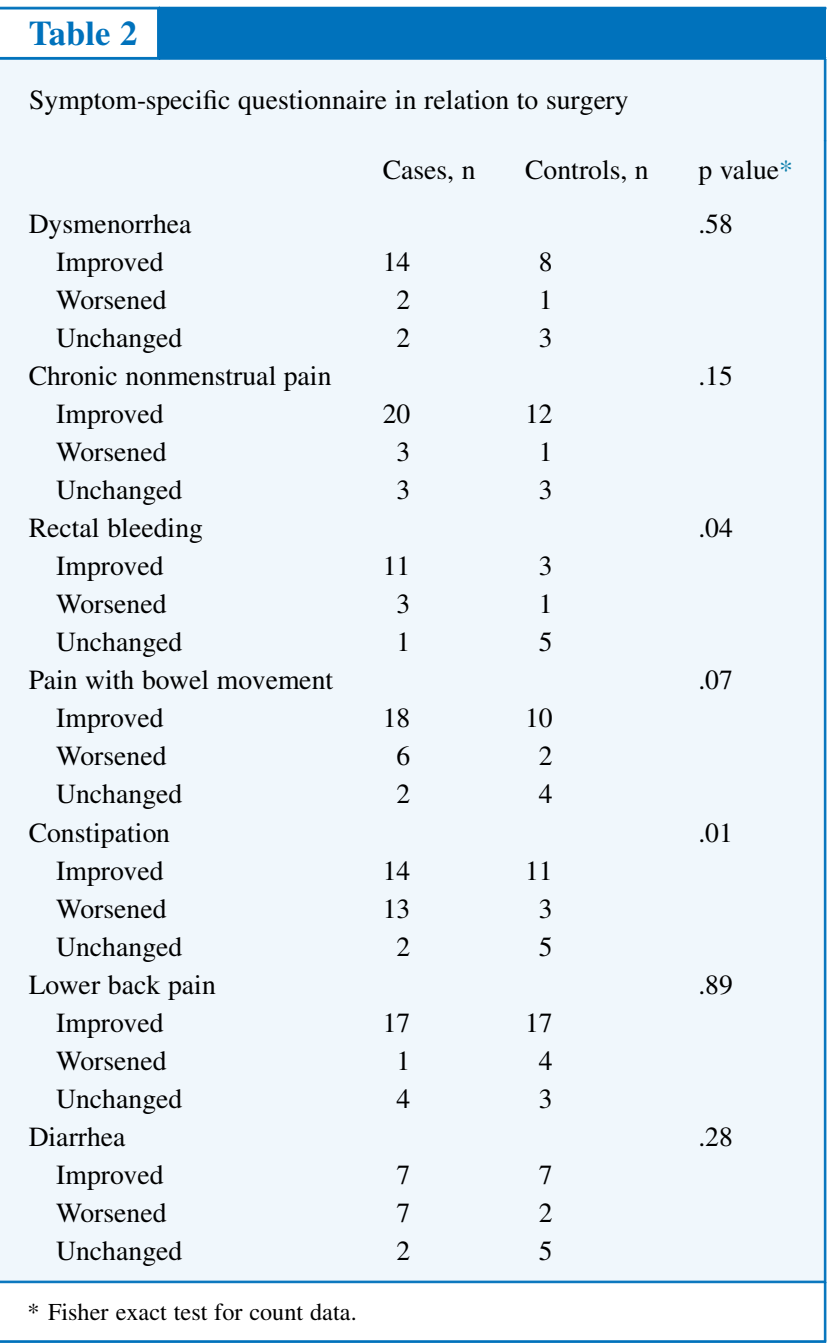

of 0.25. Matching was done by ratios of 1-to-1, 2-to-1, 3-to1, and 4-to-1, and subjects were matched without replacement. Each of these matched datasets was evaluated using Rubin's rules. Based on these evaluations, the 2-to-1

\begin{tabular}{|c|c|c|c|}
\hline \multicolumn{4}{|l|}{ Table 3} \\
\hline \multicolumn{4}{|c|}{ Postoperative status questionnaire } \\
\hline Question & $\begin{array}{l}\text { Cases, } \\
\mathrm{n} / \mathrm{N}(\%)\end{array}$ & $\begin{array}{l}\text { Controls, } \\
\mathrm{n} / \mathrm{N}(\%)\end{array}$ & $\begin{array}{l}\mathrm{p} \\
\text { value }\end{array}$ \\
\hline \multicolumn{4}{|l|}{ After surgery have you had: } \\
\hline New bowel symptoms? & $21 / 36(58)$ & $5 / 35(14)$ & $.001 *$ \\
\hline New urinary symptoms? & $13 / 36(36)$ & $10 / 35(29)$ & $.67 *$ \\
\hline $\begin{array}{c}\text { Diagnosis of irritable } \\
\text { bowel syndrome? }\end{array}$ & $6 / 36(17)$ & $5 / 35(14)$ & $.99^{\dagger}$ \\
\hline Diagnosis of cancer? & $1 / 36(3)$ & $1 / 35(3)$ & $.99^{\dagger}$ \\
\hline $\begin{array}{l}\text { Would you have the } \\
\text { same surgery? }\end{array}$ & $30 / 36(83)$ & $29 / 35(83)$ & $.74^{\dagger}$ \\
\hline
\end{tabular}




\begin{tabular}{|c|c|c|c|}
\hline Bristol Stool Form Scale and & AC-SYM score & & \\
\hline Variable & Cases & Controls & $\mathrm{p}$ value \\
\hline $\begin{array}{l}\text { Normal Bristol Stool Form } \\
\text { Scale }(2-6), \mathrm{n} / \mathrm{N}(\%)\end{array}$ & $29 / 36(81)$ & $33 / 35(94)$ & $.59 *$ \\
\hline $\begin{array}{l}\text { Total PAC-SYM score, } \\
\text { median (IQR) }\end{array}$ & $9(6-18.75)$ & $4(0-13)$ & $.029^{\dagger}$ \\
\hline PS discomfort in abdomen, $\mathrm{n}$ & & & $.21^{*}$ \\
\hline Absent & 15 & 19 & \\
\hline Mild & 14 & 7 & \\
\hline Moderate & 3 & 6 & \\
\hline Severe & 4 & 2 & \\
\hline Very severe & 0 & 1 & \\
\hline PS pain in abdomen, $n$ & & & $.005^{*}$ \\
\hline Absent & 20 & 23 & \\
\hline Mild & 12 & 3 & \\
\hline Moderate & 0 & 6 & \\
\hline Severe & 4 & 3 & \\
\hline Very severe & 0 & 0 & \\
\hline PS bloating in abdomen, $\mathrm{n}$ & & & $.63^{*}$ \\
\hline Absent & 15 & 16 & \\
\hline Mild & 11 & 7 & \\
\hline Moderate & 5 & 8 & \\
\hline Severe & 2 & 3 & \\
\hline Very severe & 3 & 1 & \\
\hline PS stomach cramps, $\mathrm{n}$ & & & $.11^{*}$ \\
\hline Absent & 19 & 23 & \\
\hline Mild & 12 & 5 & \\
\hline Moderate & 1 & 5 & \\
\hline Severe & 3 & 1 & \\
\hline Very severe & 1 & 1 & \\
\hline $\begin{array}{l}\text { PS painful bowel } \\
\text { movements, } \mathrm{n}\end{array}$ & & & $.95^{*}$ \\
\hline Absent & 19 & 23 & \\
\hline Mild & 12 & 5 & \\
\hline Moderate & 1 & 5 & \\
\hline Severe & 3 & 1 & \\
\hline Very severe & 1 & 1 & \\
\hline PS rectal burning, $\mathrm{n}$ & & & $.34 *$ \\
\hline Absent & 29 & 28 & \\
\hline Mild & 3 & 4 & \\
\hline Moderate & 1 & 3 & \\
\hline Severe & 3 & 0 & \\
\hline Very severe & 0 & 0 & \\
\hline PS rectal bleeding, $n$ & & & $.84 *$ \\
\hline Absent & 28 & 29 & \\
\hline Mild & 4 & 3 & \\
\hline Moderate & 1 & 2 & \\
\hline Severe & 2 & 0 & \\
\hline Very severe & 1 & 1 & \\
\hline $\begin{array}{l}\text { PS incomplete bowel } \\
\text { movements, } \mathrm{n}\end{array}$ & & & $.017 *$ \\
\hline Absent & 9 & 22 & \\
\hline Mild & 11 & 6 & \\
\hline Moderate & 11 & 4 & \\
\hline Severe & 4 & 2 & \\
\hline Very severe & 1 & $(C c$ & ntinued) \\
\hline
\end{tabular}

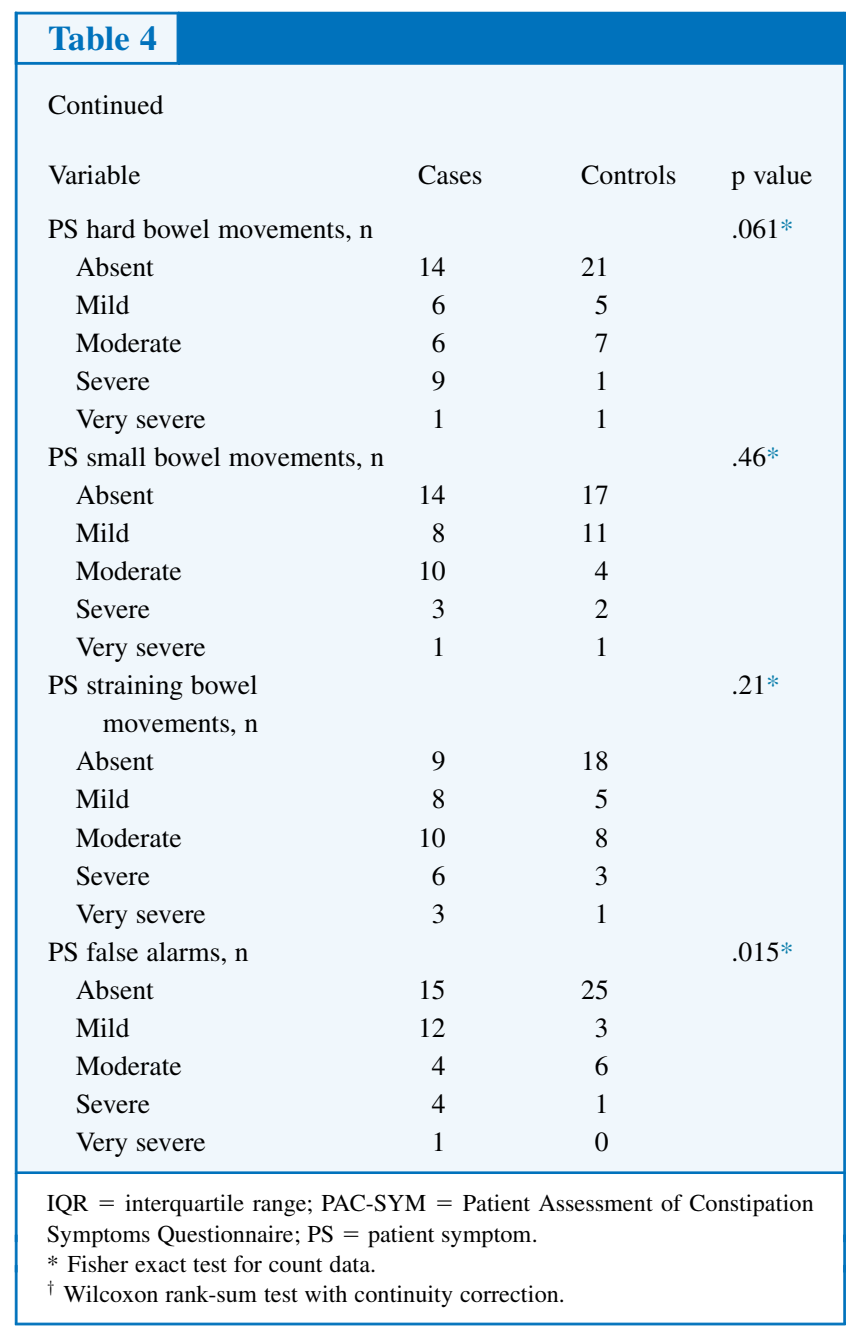

matching with a caliper of 1 provided the best match; however, because we could not guarantee that all subjects would respond to the survey, we performed 3-to-1 matching (Fig).

Once the control group surveys were returned, comparisons were performed using the Wilcoxon rank-sum test and the $\chi^{2}$ test. In cases of small frequencies, comparisons were made using the Fisher exact tests. Results were considered statistically significant at a $\mathrm{p}$ value $\leq .05$. Univariate and multivariate analyses were conducted using $R$ version 3 (R Project for Statistical Computing, Vienna, Austria). A linear mixed-effects model with matched groups serving as a random effect was applied for the multivariate analysis.

\section{Results}

The study population comprised 71 patients, including 36 cases and 35 controls. The overall response rate to the surveys was $43 \%$ (64\% for cases and 32\% for controls). The median duration of follow-up was 10.1 years (range, 4-18 years) for the cases and 10.2 years (range, 4-18 years) for the controls. The mean patient age and body mass index 
(BMI) were comparable in the 2 groups (Table 1). The proportion of patients that were African-American patients was higher in the case group (27.8\% [ 10 of 36] vs $5.7 \%$ [ 2 of 35]; $\mathrm{p}=.02$ ). The proportion of patients with preoperative dyspareunia was comparable in the 2 groups $(36.1 \%$ [13 of 36 ] vs $40 \%$ [14 of 35]; $\mathrm{p}=.80$ ). The symptoms that patients listed as the reason of the surgery were similar in the 2 groups, except that more cases reported bowel pain as a reason $(66.7 \%$ [24 of 36 ] vs $31.4 \%$ [11 of 35]; $p=.006)$.

According to the questionnaire evaluating the progression of specific symptoms in relation to surgery, a larger proportion of cases had improved rectal bleeding compared with controls (30.6\% [11 of 36] vs 8.6\% [3 of 35]; $\mathrm{p}=.04$ ) (Table 2). In addition, a larger proportion of cases reported worsened constipation (36.1\% [13 of 36] vs $8.6 \%$ [3 of 35]; $p=.04$ ).

Analysis of the postoperative status questionnaire revealed a significantly higher proportion of new bowel symptoms in cases compared with controls (58.3\% [21 of 36] vs $14.3 \%$ [5 of 35]; $p=.001$ ) (Table 3). Importantly, the proportion of patients stating that they would undergo the same surgery again was similar in the 2 groups (83.3\% [30 of 36] of cases vs. $82.9 \%$ [29 of 35] of controls; $p=.74$ ). In addition, there were no significant between-group differences in the incidence of new urinary symptoms and in the diagnosis of irritable bowel syndrome or cancer.

The proportion of patients with normal stool consistency as rated by the Bristol Stool Form Scale Score of 2 to 6 was similar in the 2 groups ( $80.6 \%$ [ 29 of 36] of cases vs $94.3 \%$ [33 of 35] of controls; $\mathrm{p}=.59$ ) (Table 4). Univariate analysis revealed a statistically higher total PAC-SYM score in the cases compared with the controls (median, 9 [interquartile range (IQR), 6-18.75] vs 4 [IQR, 0-13]; $\mathrm{p}=.029$ ). Abdominal pain, incomplete bowel movements, and false alarms were statistically more frequent in the cases (Table 4); however, the median total PAC-SYM score was similar in the 2 groups when a linear mixed-effects model with matched groups serving as a random effect was applied (Table 5). The Vaizey Fecal Incontinence Grading System score was also similar in the cases and controls (median, 8 [IQR, $8-10$ ] vs 8 [IQR, $8-10] ; \mathrm{p}=.86$ ) (Table 6 ). Correspondingly, there were no differences in the individual symptoms reported on the Vaizey questionnaire and after application of the linear mixed-effects model (Table 5).

\section{Discussion}

Our findings in this study suggest that undergoing segmental bowel resection for DIE may be associated with a higher incidence of new bowel symptoms (possibly due to abdominal pain, incomplete bowel movements, and/ or false alarms), but not with worse constipation or fecal incontinence compared with surgery without bowel resection. The treatment for severe endometriosis, particularly in patients with DIE involving the bowel, is often complex and may require a multidisciplinary surgical approach for

\begin{tabular}{|c|c|c|}
\hline \multicolumn{3}{|l|}{ Table 5} \\
\hline \multicolumn{3}{|c|}{$\begin{array}{l}\text { Comparison of cases and controls using a univariate analysis vs a } \\
\text { linear mixed-effects model with matched groups used as a random } \\
\text { effect }\end{array}$} \\
\hline & $\mathrm{p}$ value & \\
\hline Variable & $\begin{array}{l}\text { Univariate } \\
\text { analysis }\end{array}$ & $\begin{array}{l}\text { Linear } \\
\text { mixed-effects } \\
\text { model }\end{array}$ \\
\hline New bowel symptoms & $.001 *$ & $.001^{\dagger}$ \\
\hline $\begin{array}{l}\text { Normal Bristol Stool Form } \\
\text { Scale score }(2-6)\end{array}$ & $.59^{\ddagger}$ & $.083^{\dagger}$ \\
\hline Total PAC-SYM score, median & $.029^{\S}$ & $.36^{\pi}$ \\
\hline $\begin{array}{l}\text { Vaizey Fecal Incontinence } \\
\text { Grading System score, mediar }\end{array}$ & $.86^{\S}$ & $.70^{\llbracket}$ \\
\hline \multicolumn{3}{|c|}{$\begin{array}{l}\text { PAC-SYM = Patient Assessment of Constipation Symptoms Questionnaire. } \\
\text { * Pearson } \chi^{2} \text { test with Yates continuity correction. } \\
{ }^{\dagger} \text { Generalized linear mixed-effects model (odds ratio, cases vs controls). } \\
{ }^{\ddagger} \text { Fisher exact test for count data. } \\
\S \text { Wilcoxon rank-sum test with continuity correction. } \\
\text { ฯ Linear mixed-effects model (mean difference, cases vs controls). }\end{array}$} \\
\hline
\end{tabular}

symptomatic patients who do not improve with medical treatment [16-18]. Several case series involving segmental bowel resection for DIE have been reported in the literature, but these have been limited owing to a lack of validated questionnaires, small sample size, or absence of a control group that did not undergo bowel surgery [10,19-28]. Moreover, some studies have lacked longterm follow-up $[23,28]$. The purpose of the present study was to compare the long-term outcomes of patients who underwent bowel resection for DIE and matched patients with severe endometriosis using validated conditionspecific questionnaires.

The present study suggests that most patients who underwent surgical treatment for endometriosis (with [cases] or without [controls] bowel resection) experienced improvement in dysmenorrhea, chronic nonmenstrual pain, pain with bowel movements, and lower back pain. This improvement in symptoms was not statistically significantly different between the cases and the controls, however. In contrast, a larger proportion of cases than controls experienced reduced rectal bleeding after surgery. When patients were specifically asked about worsened constipation, a larger proportion of cases than controls reported this finding; however, assessment of these symptoms using a valid and reliable questionnaire (PAC-SYM) revealed no significant differences between the 2 groups. In addition, the cases and controls reported a similar proportion of normal stools as evaluated by the Bristol Stool Form Scale, indicating similar stool consistency and transit times. With respect to stool incontinence (Vaizey Fecal Incontinence Grading System), patients who underwent bowel resection did not report a higher incidence of fecal incontinence compared with controls. 


\begin{tabular}{|c|c|c|c|}
\hline \multicolumn{4}{|l|}{ Table 6} \\
\hline \multicolumn{4}{|c|}{ Vaizey Fecal Incontinence Grading System results } \\
\hline Variable & Cases & Controls & $\mathrm{p}$ value \\
\hline Vaizey score, median (IQR) & $8(8-10)$ & $8(8-10)$ & $.86^{*}$ \\
\hline Incontinence for solid stools, $\mathrm{n}$ & & & $.25^{\dagger}$ \\
\hline Never & 28 & 32 & \\
\hline Rarely & 0 & 1 & \\
\hline Sometimes & 2 & 1 & \\
\hline Weekly & 4 & 1 & \\
\hline Daily & 2 & 0 & \\
\hline Incontinence for liquid stools, $\mathrm{n}$ & & & $.21^{\dagger}$ \\
\hline Never & 27 & 30 & \\
\hline Rarely & 2 & 4 & \\
\hline Sometimes & 3 & 0 & \\
\hline Weekly & 2 & 1 & \\
\hline Daily & 2 & 0 & \\
\hline Incontinence for gas, $\mathrm{n}$ & & & $.85^{\dagger}$ \\
\hline Never & 17 & 14 & \\
\hline Rarely & 4 & 7 & \\
\hline Sometimes & 7 & 6 & \\
\hline Weekly & 2 & 3 & \\
\hline Daily & 6 & 5 & \\
\hline Altered lifestyle, $\mathrm{n}$ & & & $.23^{\dagger}$ \\
\hline Never & 27 & 32 & \\
\hline Rarely & 3 & 2 & \\
\hline Sometimes & 3 & 0 & \\
\hline Weekly & 1 & 1 & \\
\hline Daily & 2 & 0 & \\
\hline Pad or plug use, $n$ & & & $.11^{\dagger}$ \\
\hline Yes & 4 & 0 & \\
\hline No & 32 & 35 & \\
\hline Constipating medication use, $\mathrm{n}$ & & & $.36^{\dagger}$ \\
\hline Yes & 4 & 1 & \\
\hline No & 32 & 34 & \\
\hline $\begin{array}{l}\text { Inability to defer defecation } \\
\text { for } 15 \mathrm{~min}, \mathrm{n}\end{array}$ & & & $.28^{\dagger}$ \\
\hline Yes & 12 & 7 & \\
\hline No & 24 & 28 & \\
\hline $\begin{array}{l}\text { IQR }=\text { interquartile range. } \\
* \text { Wilcoxon rank-sum test with conti } \\
{ }^{\dagger} \text { Fisher exact test for count data. }\end{array}$ & y correction & & \\
\hline
\end{tabular}

Regarding patient satisfaction, a similar proportion of cases and controls reported that they would undergo the same surgery again. Nevertheless, the cases were more likely than the controls to report new bowel symptoms. Presumably, these symptoms were abdominal pain, incomplete bowel movements, and false alarms, which were statistically more frequent in the cases (Table 4). Before undergoing bowel resection, patients should be counseled about the risk of developing these new symptoms after surgery.

Limitations of the present study include the potential for selection or recall bias owing to the study's retrospective and single-institution design, relatively small sample size, and low response rate to the surveys. The small sample size was due to the strict inclusion criteria, that required at least a 4-year follow-up. Nonetheless, it is possible that this study was underpowered to detect smaller, clinically significant differences, or that these symptoms diminished over time after surgery. Moreover, other surgical modalities for treating DIE involving the bowel, such as shaving or discoid resection of lesions, were not performed and thus are not included in our analysis.

The low overall response rate to the surveys (43\%) occurred despite systematic attempts to contact both cases and controls. An important contributing factor was the inability to contact many patients at the available address or a forwarding address, given the study's long time span (14 years).

Despite these limitations, however, this study represents an important addition to the literature given the distinctive strengths of long-term follow-up (median follow-up $>10$ years), use validated questionnaires, and inclusion of matched controls.

Future studies to evaluate the role of bowel surgery for DIE should consider including pain scores as well as overall quality of life markers in addition to validated bowel function questionnaires.

In conclusion, segmental bowel resection for DIE appears to be associated with a higher incidence of new bowel symptoms compared with surgery for advanced endometriosis without bowel resection (possibly owing to abdominal pain, incomplete bowel movements, and/or false alarms). The incidence of constipation or fecal incontinence is similar in these 2 groups of patients, however.

\section{Acknowledgments}

We thank Benjamin Nutter for his assistance with the statistical analyses.

\section{References}

1. Koninckx PR, Meuleman C, Demeyere S, Lesaffre E, Cornillie FJ. Suggestive evidence that pelvic endometriosis is a progressive disease, whereas deeply infiltrating endometriosis is associated with pelvic pain. Fertil Steril. 1991;55:759-765.

2. Chapron C, Chopin N, Borghese B, Foulot H, Dousset B, VacherLavenu MC, et al. Deeply infiltrating endometriosis: pathogenetic implications of the anatomical distribution. Hum Reprod. 2006;21: 1839-1845.

3. Weed JC, Ray JE. Endometriosis of the bowel. Obstet Gynecol. 1987; 69:727-730.

4. Macafee $\mathrm{CH}$, Greer HL. Intestinal endometriosis. A report of 29 cases and a survey of the literature. J Obstet Gynaecol Br Emp. 1960;67: 539-555.

5. Fauconnier A, Chapron C, Dubuisson JB, Vieira M, Dousset B, Bréart G. Relation between pain symptoms and the anatomic location of deep infiltrating endometriosis. Fertil Steril. 2002;78:719-726.

6. Nezhat C, Hajhosseini B, King LP. Laparoscopic management of bowel endometriosis: predictors of severe disease and recurrence. JSLS. 2011; 15:431-438.

7. Daraï E, Dubernard G, Coutant C, Frey C, Rouzier R, Ballester M. Randomized trial of laparoscopically assisted versus open colorectal resection for endometriosis: morbidity, symptoms, quality of life, and fertility. Ann Surg. 2010;251:1018-1023. 
8. Mereu L, Ruffo G, Landi S, Barbieri F, Zaccoletti R, Fiaccavento A, et al. Laparoscopic treatment of deep endometriosis with segmental colorectal resection: short-term morbidity. J Minim Invasive Gynecol. 2007; 14:463-469.

9. Minelli L, Fanfani F, Fagotti A, Ruffo G, Ceccaroni M, Mereu L, et al. Laparoscopic colorectal resection for bowel endometriosis: feasibility, complications, and clinical outcome. Arch Surg. 2009;144:234-239.

10. Dubernard G, Piketty M, Rouzier R, Houry S, Bazot M, Darai E. Quality of life after laparoscopic colorectal resection for endometriosis. Hum Reprod. 2006;21:1243-1247.

11. Thomassin I, Bazot M, Detchev R, Barranger E, Cortez A, Darai E Symptoms before and after surgical removal of colorectal endometriosis that are assessed by magnetic resonance imaging and rectal endoscopic sonography. Am J Obstet Gynecol. 2004;190: 1264-1271.

12. Roman H, Loisel C, Resch B, Tuech JJ, Hochain P, Leroi AM, et al. Delayed functional outcomes associated with surgical management of deep rectovaginal endometriosis with rectal involvement: giving patients an informed choice. Hum Reprod. 2010;25:890-899.

13. Degen LP, Phillips SF. How well does stool form reflect colonic transit? Gut. 1996;39:109-113.

14. Vaizey CJ, Carapeti E, Cahill JA, Kamm MA. Prospective comparison of faecal incontinence grading systems. Gut. 1999;44:77-80.

15. Frank L, Kleinman L, Farup C, Taylor L, Miner P Jr. Psychometric validation of a constipation symptom assessment questionnaire. Scand J Gastroenterol. 1999;34:870-877.

16. Abräo MS, Petraglia F, Falcone T, Keckstein J, Osuga Y, Chapron C. Deep endometriosis infiltrating the recto-sigmoid: critical factors to consider before management. Hum Reprod Update. 2015;21: 329-339.

17. Rausei S, Sambucci D, Spampatti S, Cassinotti E, Dionigi G, David G, et al. Laparoscopic treatment of deep infiltrating endometriosis: results of the combined laparoscopic gynecologic and colorectal surgery. Surg Endosc. 2015;29:2904-2909.

18. Wolthuis AM, Tomassetti C. Multidisciplinary laparoscopic treatment for bowel endometriosis. Best Pract Res Clin Gastroenterol. 2014;28:53-67.
19. Klugsberger B, Shamiyeh A, Oppelt P, Jabkowski C, Schimetta W, Haas D. Clinical outcome after colonic resection in women with endometriosis. Biomed Res Int. 2015;2015:514383.

20. Ruffo G, Scopelliti F, Manzoni A, Sartori A, Rossini R, Ceccaroni M, et al. Long-term outcome after laparoscopic bowel resections for deep infiltrating endometriosis: a single-center experience after 900 cases. Biomed Res Int. 2014;2014:463058.

21. Song W, Yao S, Chen S, Han F, He Y. Clinical efficacies of laparoscopic-assisted rectal resection and transvaginal removal for middle or low rectal endometriosis. Zhonghua Yi Xue Za Zhi. 2014;94: 131-133 (in Chinese).

22. Roman H, Vassilieff M, Tuech JJ, Huet E, Savoye G, Marpeau L, et al. Postoperative digestive function after radical versus conservative surgical philosophy for deep endometriosis infiltrating the rectum. Fertil Steril. 2013;99:1695-1704.

23. Kössi J, Setälä M, Mäkinen J, Härkki P, Luostarinen M. Quality of life and sexual function 1 year after laparoscopic rectosigmoid resection for endometriosis. Colorectal Dis. 2013;15:102-108.

24. Boileau L, Laporte S, Bourgaux JF, Rouanet JP, Filleron T, Mares P, et al. Laparoscopic colorectal resection for deep pelvic endometriosis: evaluation of post-operative outcome. J Gynecol Obstet Biol Reprod (Paris). 2012;41:128-135 (in French).

25. Pereira RM, Zanatta A, Preti CD, de Paula FJ, da Motta EL, Serafini PC. Should the gynecologist perform laparoscopic bowel resection to treat endometriosis? Results over 7 years in 168 patients. J Minim Invasive Gynecol. 2009;16:472-479.

26. de Jong MJ, Mijatovic V, van Waesberghe JH, Cuesta MA, Hompes PG. Surgical outcome and long-term follow-up after segmental colorectal resection in women with a complete obstruction of the rectosigmoid due to endometriosis. Dig Surg. 2009;26:50-55.

27. Seracchioli R, Poggioli G, Pierangeli F, Manuzzi L, Gualerzi B, Savelli L, et al. Surgical outcome and long-term follow up after laparoscopic rectosigmoid resection in women with deep infiltrating endometriosis. Br J Obstet Gynaecol. 2007;114:889-895.

28. Duepree HJ, Senagore AJ, Delaney CP, Marcello PW, Brady KM, Falcone T. Laparoscopic resection of deep pelvic endometriosis with rectosigmoid involvement. J Am Coll Surg. 2002;195:754-758. 